\title{
Learner-Centered Teaching and Teaching Statistics in Social Sciences
}

\section{Enseñanza centrada en el estudiante y enseñar estadística en Ciencias Sociales}

\section{Celestino Fernández and Ricardo Rivas ${ }^{1}$}

\begin{abstract}
This paper critically reviews the main principles of the learner-centered teaching approach. In doing this, we focus on statistics as educational content for students in the social sciences. This content was selected because, generally, the structure of the content would suggest that employing active learning in the teaching of statistics would be very difficult. In this paper, we review different theoretical and empirical contributions to learner-centered teaching of statistics in the social sciences presenting some examples from the field of Sociology. Finally, a brief theoretical framework and some research questions are proposed for undertaking further research in this area.
\end{abstract}

\section{Keywords}

Higher education, learner engagement, student attitudes, teaching methods, constructivism, learner-centered teaching.

\section{Resumen}

Este ensayo revisa críticamente los principios centrales del enfoque de enseñanza centrada en quien aprende. Para esto, nos centramos en la estadística como contenido educacional para estudiantes de educación superior en el área de ciencias sociales. Este contenido fue escogido porque en general se trata de un contenido altamente estructurado, lo que nos hace suponer que emplear aprendizaje activo es más difícil. En este artículo revisamos diferentes contribuciones teóricas y empíricas al enfoque de enseñanza centrada en quien aprende aplicado a la enseñanza de la estadística en las ciencias sociales presentando algunos ejemplos del campo de la sociología. Finalmente, entregamos una propuesta de un breve marco teórico y algunas preguntas de investigación parar futuras investigaciones en esta área.

\section{Palabras clave}

Educación superior, aprendizaje activo, actitudes del estudiante, métodos de enseñanza, constructivismo, enseñanza centrada en quien aprende. 


\section{Introduction}

Ana Louise Keating states in her book, Teaching Transformation (2007: 9), that «Classrooms are, potentially, places of change. What, specifically, these changes entail is context-specific and open to negotiation.» Her statement summarizes the core of this paper, which presents a perspective of teaching within particular contexts. Specifically, we wonder if teachers can foster participation and critical thinking - as new teaching perspectives claim - in math or statistics classes. Other related questions include: Is it easier to teach critical thinking in the humanities or social sciences? Are approaches to teaching based on constructivism pertinent to all types of subjects? Weimer (2013) alludes to these questions in the following excerpt:

The idea that students might be involved in knowledge construction fits comfortably in the humanities and social science fields, where content supports more tentative and less definitive conclusions. It is more difficult to see how knowledge can be «socially» constructed in science, math, and engineering fields, where there are more «right» answers and much less disagreement about the status of knowledge. As a consequence, objections to constructivist theories came first from these fields, although at this point they have been raised by educators in many fields. (p. 22).

Therefore, it is worthwhile to explore what may be going on in the teaching of statistics. Statistics matter, as do many other subjects, in an era where information is a critical capital for people, organizations and greater entities, including nation states. But also, teaching statistics is relevant in this work because it is probably the most structured subject in the social sciences. Since the foundation of statistics is in mathematics, there exist several assumptions, laws and principles which are not challenged in the social sciences. This «axiomatic thinking» (Blalock, 1987) implies by inertia teaching that is centered on content in a field where there is little room for critical and active learning. On the other hand, the diffusion of new styles of teaching at all levels is changing perspectives on processes, content and actors regarding teaching and learning.

There are good reasons, such as the low retention on knowledge among other educational aims (Barkley, 2010), to change the way that instructors and organizations teach. This change takes into account highly structured fields of knowledge like statistics. Nevertheless, as with any perspective or paradigm focused on social change, there are some caveats regarding the implementation of interventions. This paper is intended to inform about relevant scholarly work in higher education on the teaching of statistics in the social sciences, having as reference some basic principles and limitations of the learner-centered approach. Within this context, some research questions are put forward in the final section of this paper.

\section{Teaching Statistics in Social Sciences}

The concern about teaching among scholars in social sciences has been moved into statistics as a specific field. In higher education, it is important that students of social sciences and also other disciplines like public health use quantitative methods in an active way, which means doing research beyond learning mathematical formulas (Strangfeld, 2013). However, there several issues that any statistics' teacher has to overcome. In this regard foundational work was undertaken by Hubert Blalock (1987). Blalock wrote important manuals on social statistics; hence, his reflections regarding teaching statistics and associated problems impacted the scholarly community in the 1980s. According to Blalock, there are crucial pedagogical objectives for any statistics' instructor which can be briefly described as follows: 
1. Overcoming resistance and over-memorization of content in statistics' courses: Since, generally, many students have some resistance toward math and quantitative science, a pragmatic way to pass courses on such subjects is through memorization. The problem is that when memory fails, as can often be the case, the reasoning process is blocked because students bave not learned to reason, only to memorize. Blalock states that «statistics courses also provide excellent opportunities to stress the difference between an active and passive mode of learning.» (p. 165).

2. Honesty and Integrity: these values are related to the important decisions that professional needs to make relative to the use of statistics. Teaching statistics implies also teaching attitudinal aspects regarding using data and the results from analyses.

3. Teaching deductive-inductive inference as a logical and transversal process: the deductive process is based on technical knowledge about techniques and basic rules. Advantages and disadvantages of specific procedures of inference, causation, etc. need to be taught as the basis for the next steps in social research.

4. Critical and reasonable thinking with respect to statistics: there are no templates to make decisions. All research implies trade-offs. For instance, researchers can favor parsimony over validity of results according to the criteria that they embrace. Students need to have an adequate understanding of this kind of flexibility without losing thoroughness.

5. Handling complexities systematically: this means that statistics is a reduction of complexity, therefore, some error, even if minor, is likely. In this context, avoiding empiricist exercises is an issue in the formation of prospective researchers. It is necessary to help students learn that statistics are an important tool that assists in understanding the complexity of social reality (with theoretical guidance).

Before reviewing some of the aforementioned pedagogical objectives further, it is important to look first at how American scholarly research has covered the issue of the teaching of statistics.

\section{Research on Teaching Statistics}

In the 2000s, one can find literature more directly related to the teaching of statistics in the context of Sociology. DeCesare (2007) argues that the problems associated with teaching and learning statistics have been based on informal knowledge, as there is a lack of scientific knowledge in this regard. In order to overcome this shortcoming, DeCesare carried out an empirical research study that found that anxiety is related to student's gender (female) and the students' expected course grades. Similarly, Delucchi (2007, 2014) also put forward some criticism, claiming that in general, assessment of statistics courses and some strategies in the classroom are based on self-reported responses of student or faculty perceptions, which are, in short, only perceived knowledge. Therefore, Delucchi (2014) included a pre-test and post-test in his research in order to assess the impact of statistics courses on learning. He found that courses are relevant insofar as students are motivated, once they can get beyond anxiety and other psychological barriers.

Beyond the technical quality of these research articles and their interesting results, there is not a clear theoretical approach to teaching as social practice. Thus, it is necessary to consider some basic theoretical underpinnings capable of giving coherence to these questions and findings. In this regard, the learnercentered approach has emerged as a prominent framework, amidst various teaching perspectives. 


\section{Learner-Centered Approach}

According to Weimer (2013), learner-centered teaching is not a single theory or philosophy. Rather, there are multiple components of theories from different disciplines that support active learning processes. The author mentions several, including attribution theory and the concept of self-efficacy from social psychologists; the idea of critical pedagogy from Paulo Freire; feminist theory from gender equality social movements; constructivism from classical authors such as Piaget or Vygotsky; and less known theoretical contributions such as the concept of transformative learning. However, based on both Weimer (2013) and Yilmaz (2008), one can conclude that constructivism is at the core of the learner-centered perspective. This theory cannot be understood without the assumption that students have to build their own knowledge and meanings upon the elements that they obtain from teachers and learning materials such as textbooks. Also, a learner-centered approach takes from constructivist principles the reciprocal relationship between the content (quality and quantity) and the cognitive process that students carry out to obtain significant learning.

All these theoretical contributions are gathered under the principle of students as active learners. The main components of a learner-centered approach are the creation of an educational context based on student engagement, motivation, empowerment, collaboration, and reflection.

In order to better understand this approach, the next section is devoted to a critical review of theoretical and practical ideas around four aspects related to teaching based on previous literature (Bessant, 1992; Delucchi, 2014; Paxton, 2006; Strangfeld, 2013): 1) students' psychological traits; 2) teacher's role; 3) subject's content; and 4) assessment.

\section{1. Students' Psychological Traits: Developmental Maturity}

Weimer (2013) focuses on how the teaching-learning process interacts with the developmental traits of students. The main idea is that teachers and their strategies (including assignments and activities) are connected not only with the intellectual dimension of students but also to their personality development. The goal is for the learning process to develop autonomy and self-direction in students. However, according to the author, there are some caveats (p. 219):

1. It is not automatic: students do not necessarily achieve some levels of maturity at the first opportunity to develop associated skills.

2. It does not happen at a predictable pace: progress has different rhythms and depends on various factors.

3. It is not linear: there might not be any progress for some time and, then suddenly, one can see a significant increase of progress; and

4. It does not happen quickly: to achieve high levels of autonomy or self-regulation one course is not enough. It is a process that unfolds over time as students are exposed to learning.

Grow (1991) quoted by Weimer (2013) identifies some specific steps as with any process of development. In each of these steps, the teacher can intervene with different strategies. It is important to know how to detect in which category students are located.

This development requires that instructors guide students, stimulating and fostering autonomy and responsibility with respect to the process of learning. For instance, Blalock (1987) points out interesting elements with reference to advantages and disadvantages of daily exercises to reinforce the learn- 
ing of statistics content. Despite the fact that the author is not specific regarding these types of exercises, in general he claims that they are useful in order to avoid «cramming» but, they imply personal habits that will not be acquired through a single course. Implicitly, the results of these types of activities depend on which of Grow's stage students are in. In this regard, Potter (1995) underpins various teaching techniques on the notion that students have to be active in the context of a contract wherein both parties (teacher and students) have to fulfill responsibilities. Since there is enough documented evidence that the more students are involved in doing statistics the more they learn, the challenge is how to engage them. The author exposes tips and caveats with respect to practices in the classroom such as «call and response», problem solving, and small group work. Also, Halley (1991) highlights how simulation software allows students to learn about research under different simulated scenarios of data distributions ${ }^{2}$. Also, students can make decisions about their learning. This is because students are able to work with «self-instructional materials such as programmed texts and laboratory exercises [which] are used to guide students in learning the material. When students feel they are ready, they request an examination on a single unit» (p. 522).

\subsection{Students' Psychological Traits: Anxiety and Motivation}

Anxiety and motivation are two important psychological characteristics of students that matter in teaching quantitative subjects such as statistics. It is possible to find different techniques in the scholarly literature to address these sentiments in order to create a positive environment for learning.

Anxiety has been a critical topic (Onwuegbuzie y Wilson, 2003; Schacht y Stewart, 1990) that has gained the attention of several scholars, especially after Blalock's work in 1987. As mentioned before, anxiety is a common feeling that students experience when they encounter courses with quantitative requirements such as math and statistics. Anxiety experts note that the effects of anxiety result in blocking the flux of information between the «memory bank» and the «input area» that allow people to solve math problems (Tobias, 1987).

Over-memorization has been a «way out» for students facing anxiety in statistics classes (Blalock 1987). Regular practical exercises should help avoid over-memorization. In the 1990s, teachers found a good support system in software. Halley (1991), Karp (1995), and Smith (2003) have shown over time the benefits of software in teaching statistics. These authors promote the use of software because it provides more opportunities to learn by completing practical exercises ${ }^{3}$. The pedagogical rationale is that introductory statistics courses should avoid math theory and memorization and promote practical exercises.

However, the most effective strategy against anxiety is to foster student engagement. Essentially, engagement is about motivation and this means that the individual wants to learn. A motivated student will be more active in the learning process and receptive to new ways to undertake learning. To lecture/teach that goes beyond surface learning means to challenge minds and harness emotions (Timpson y Burgoyne, 1982) such as identity and belonging (Masika y Jones, 2016). Therefore, motivation, like other psychological issues has to be conceived as something to be managed.

2 In this regard, it is worthwhile to keep in mind that there is a difference between teaching computing and teaching research (Markham, 1991).

3 On the other hand, authors like Hurlburt (1993) gives examples of practical exercises without using software. The author puts forward the idea of «eyeballestimation.» The objective is to have students calculate statistics preceding computer assistance. According to Hurlburt, this is a good way to grasp the logic behind statistical analysis and is also a way of encouraging active learning. Obviously, these types of exercises need small data sets. 
Motivation can be fostered by instructors and depends on different contextual aspects or situations. Based on Barkley (2010: 81), there are six different aspects related with the level of students' motivation:

1. Students could want to learn on their own with the support of other resources: If very reclusive students do not want to be in class, they can learn on their own but that is a bigger challenge and responsibility for them. This alternative for students requires a high level of flexibility and probably works only in specific contexts. And, there are some risks; for instance, a student's own approach could be over-memorization, which is not a means for successful learning.

2. Teacher personality: the learner-centered approach certainly requires specific «soft skills» from teachers in order to create motivational contexts. However, this does not necessarily mean that there is a unique personality to better carry out this approach in the classroom.

3. Praise (good job) and careful criticism: reinforcement is necessary and may be the elemental incentive in the classroom. However, as the author states, criticism is the other essential face of the coin.

4. Consider students' basic needs: This principle might not be as relevant in wealthy societies such as the U.S. but it still applies here given the high level of poverty in many communities. Scholars concerned about education in poor countries need to keep in mind a basic principle of hierarchical needs, as Abraham Maslow stated in the 1950s. For instance, Stenberg (2007), studying how culture and social context affect standardized educational assessment in developing countries, claims that «failure of children to thrive in school may reflect ill health, not lack of ability» (p. 14).

5. Careful competition: Competition might be controversial within the values of the learner-centered approach because this is a way that could neglect cooperation and other human values. However, competition among groups, rather than among individuals, can be considered a source of motivation without detriment to collective learning.

6. Teacher's expectations: Different studies have demonstrated that teachers' expectations matter in explaining students' achievements (Kaplan y Owings, 2013).

Taking the previous points into consideration, specific techniques are necessary to engage students. Schacht and Stewart (1990) recommend the use of humor through cartoons in order to make statistics relevant and attractive for students and to help decrease the level of anxiety with technical and quantitative issues. However, these authors do not mention active learning as an objective. Although the use of humor is a creative way to provide examples, it does not seem to go beyond reducing anxiety. Two years later, Schacht and Stewart (1992) proposed something similar. They promote the concept of «teaching gimmicks» in both classwork and homework assignments. Similar to the use of cartoons, the objective is to create or use funny tools to present statistics examples or problems. In this article, the authors do mention that the ultimate goal is to give students a more active role in the design of examples and exercises. They review absurd situations found in cartoons and propose analytical statistical techniques to review those types of situations. In this way, students strive to provide statistical perspectives on trivial situations, reviewing contents that commonly are taught through normal lectures. Paxton (2006) recommends something more realistic. According to this author, it is useful to make statistics meaningful, while avoiding complex math. The author gives the example of reviewing statistical data on occupations and average salaries. The objective of this technique is twofold because it 
promotes the usefulness of statistics to improve the qualifications of students studying sociology and uses statistics exercises with real data, helping make students more aware of important social issues.

However, focusing on anxiety and motivation as the only problems in the learning/teaching of statistics casts some doubts. Steven Helmericks (1993) wonders if the problem is actually anxiety or, rather, a legitimate fear that affects students when they learn statistics. Focusing on other factors beyond students' attitudes, it is possible to note that there are structural aspects related to barriers in the classroom to teaching and learning statistics. In addition, there are different types of learning (affective and cognitive) and there might be different independent variables (academic and non-academic) involved that help explain the outcomes related to learning statistics (Neuman, 1989). Therefore, factors associated to students' attitudes and practices might neglect structural aspects present at the organizational level. One of these factors is the third consideration alluded to previously in this article, as identified by Bessant (1992): namely, teacher's qualifications.

\subsection{Teacher's Role and Qualifications}

With respect to the role of the teacher, the metaphors of a teacher as a maestro of an orchestra or midwife are used to denote something similar to the concept of Maieutics used by Socrates. Through this approach, teachers build context for teaching and learning based on horizontal and democratic principles. In this regard, Weimer (2013) states that «faculty encourages students to learn from and with each other» (p. 81).

The expected role of learner-centered teachers can be understood by reviewing Weimer's concept of «developmental design.» This approach is basically using a set of assignments and activities for supporting the development of independent learners. It is a twofold process as follows:

Progressive design: the level of challenge that a pedagogical activity, driven by instructors, needs to be progressive. A teacher should be able to detect the level of development of students and, according to this diagnostic, implement a certain level of complexity and demand for autonomy.

Learning skill development: any development process is slow and not linear. Teachers should not expect that one activity can foster autonomy or self-regulation in students. Therefore, activities should be related to, and build on each other and also, teachers need to identify the critical skills that are expected to be fostered in a specific assignment or activity.

Complementing the previous two points, Weimer adds some advice with respect to good practices to implement with learner-centered teaching. The first is to begin with activities that motivate rather than frustrate students. Also, teachers should begin with only one activity and immediately observe what happens. Finally, all activities or techniques should be practiced only if the teacher knows that students are ready for them.

Macheski and colleagues (2008) state that any strategy or technique used to teach statistics should combine theory and data analysis as well as promote active learning. Having stated that, the authors then put forward a concerted strategy: «faculty communities.» This concept means that teachers should not always act in isolation. Rather, action should be through discussion and decisions among the community of faculty teaching methods and statistics courses and there should be consensus on the following aspects: 
1. Active role of students;

2. Common language of discourse among teachers; and

3. Supportive emotional environment.

Besides the expectation that teachers be learner-centered instructors, teacher qualifications are another important dimension. Qualifications should be understood in a broad sense. Teacher qualifications are not only about technical skills but also personal attitudes and interpersonal skills that teachers can exert in the classroom, either by means of personal characteristics or through organizational constraints. For instance, Markham (1991) points out his concern with respect to the lack of support among colleagues when they teach methods or lack of guidance for instructors who teach about methods in the first course in some colleges. More recently, Wilder (2010) found that faculty resistance to innovation regarding teaching strategies is the most significant barrier to learning statistics. However, there is evidence that training of college teachers has demonstrated to be effective in order to promote better practices of teaching and assessment in the classroom (Renta-Davids, JiménezGonzález, Fandos-Garrido, y González-Soto, 2016).

\subsection{Subject's Content}

Good quality with reference to content is not necessarily related to quantity of content. The latter is manifested by the concept of «cover» in different types of documents such as syllabi (Weimer 2013). Teachers can cover all the content that they consider important with relation to a specific subject or issue. However, this does not necessarily mean that they are promoting learning skills in students. As might be expected, content may be very interesting for teachers but often teachers do not understand how much content is enough to achieve the learning objectives. The importance that the learnercentered approach gives to learning skills, aside from content retention, can be based on sociological reasons. According to Manuel Castells (2004), we are living in a society based on a new technology paradigm called «informationalism.» Technology has allowed us to obtain information easily wherever and whenever we need it. Under this diagnostic, everyone really needs critical thinking skills. We need analytical skills to deal with greater and greater amounts of information. Therefore, content-oriented teaching is misleading from the learner-centered approach.

Another important consideration is the essential characteristics of statistics as a teaching subject. This is a subject featuring «path dependency,» which means that a specific content cannot be understood without the understanding of previous elements. Therefore, the basis of statistics is crucial to being able to understand the rest of the content. Some research in this regard, however, concludes that, in general, the time devoted to teach basic statistics in introductory courses is not enough (Wybraniec y Wilmoth, 1999). Markham (1991) emphasizes exercises to be completed in class focused on the general logic of scientific research. According to the author, students should be familiar with the whole process prior to taking additional steps in an introductory statistic course. As it was previously noted, given the "path dependency» characteristic of statistics courses, it is necessary to look at the «general map» in order to ensure significant learning in specific subsequent courses. However, this raises other issues regarding the difference between students studying statistics as part of a major and others taking a statistics course as an isolated subject.

On the other hand, the abstract level of statistics needs concrete ways of teaching this subject. According to Potter (1995), statistics is part of people's daily life and everyone is a consumer of statistics 
at some level. Thus, too much abstraction might prevent students from gaining a practical sense of the applicability of statistics. According to Potter, approaching statistics as a foreign language is appropriate because it pushes instructors to be interactive in a field that is very strange for students but at the same time involves several aspects of their personal and professional lives.

Auster (2000) focused on a very specific content of statistics, using a ludic formula. Teaching probability sampling theory has been challenging for teachers and this topic has been poorly developed by textbooks. The author proposes the use of candy (specifically, M\&Ms) to teach in a way that would be attractive to students. She proposes this product in particular because each bag of M\&Ms contains pieces of candy with different colors that are distributed randomly. This feature facilitates the teaching of sampling theory. In this way, the author encourages creativity to teach highly abstract content in statistics.

Other instructors propose what they consider to be more realistic approaches. De Maio (2014), for example, advises using real data such as on income inequality or mortality in North America. Schumm and colleagues (2002) also embrace the idea that students need to learn statistics with some sense of its usefulness. They gather interesting and popular historical facts to get students' attention and induce motivation. Some tragic historical facts such as the Titanic sinking, the attack on Pearl Harbor or the Challenger explosion are chosen as the basis for teaching statistical concepts. Previous analysis of archives on these cases was carried out in order to generate a small data set. This, then, allows teaching probabilities and testing hypotheses with some theoretical background, but the main goal is to garner student motivation and concentration through a novel perspective regarding well-known historical incidents.

Finally, it is important to take into account that the relationship between students and statistics is not only technical. Previous examples have emphasized using a friendly approach to the acquisition of knowledge, particularly regarding conceptual and practical comprehension of statistics. However, as Blalock (1987) claims, honesty and integrity are important principles to process data and present results (Blalock 1987). Ethical aspects should be fully integrated with respect to teaching/learning of technical knowledge and fully integrated into assessment systems.

\subsection{Assessment}

According to Weimer (2013), assessment should be a process of active learning. This means that all assignments, quizzes, and exams should be centered on the learning process rather than grades. This does not mean that grading is unimportant or that teachers should withdraw from undertaking this task. Instead, teachers should strive for a greater balance between learning and grades.

Weimer warns that grades have to be understood carefully. Grades do not measure important values such as effort, good habits, or hard work. Therefore, teachers should not give the importance that, in general, is given to grades in order to avoid having grades become the goal rather than a means for learning. Weimer states that the over-consideration of grades creates «grade-oriented students;» under this logic, a teacher should not be surprised that many students attempt to cheat. Rather, teachers should foster self- and peer-assessment skills. Students should have a role in the evaluation process as part of their education in order to learn to take responsibility for the quality of their work. This is a skill appreciated in college and in the labor market, that allows students «to accurately assess the 
quality of one's own work as well as that of others» (p. 175). The value behind self-assessment is an «appraisal for expertise» which promotes the love for, and commitment to improving and to help others to do the same.

In the teaching of sociology, Delucchi (2014) promotes the use of pre- and post-tests in order to measure learning attainment as well as to revise syllabi and implement introductory courses with a better sense of the starting point for content. Delucchi identifies some elements for future research; namely, including different types of institutions and student populations in the samples as well as employing experimental methods, given that most research is undertaken with reduced student or faculty populations.

Helmericks (1993) claims that in the context of teaching statistics, it is necessary to both challenge traditional ways of teaching in school environments and to foster collaborative learning groups, and even collaborative testing. Helmericks strongly advocates for working in groups, stating that «collaborative testing, which extends the logic of collaborative learning, offers a radical shift from the traditional format; it not only humanizes the testing process but also makes it a valuable learning experience as well» (p. 290). Halley (1991), who was referenced before, recommends taking advantage of the expansion of technology and specific software to improve the teaching of statistics as well as assessment. Simulation software, for example, can create personalized data-sets that generate different results, allowing teachers to carry out comparative work groups and prevent plagiarism.

\section{Conditions}

In a learner-centered approach, there are conditions that constrain an educational project. All projects are embedded in three systems that form the context. The first comprises social characteristics related to institutions and the structure of the distribution of rewards. Second, there is a system of beliefs and meanings that drive human action, that which is considered to be culture. Finally, there is a meso-level, which is organizational. Educational projects respond to specific norms, incentives and sanctions framed by an organizational mission or aim.

These three contexts are used to highlight the main limitations that learner-centered teaching can face. The primary literature for this section was found in scholarly research attempting to define the limitation of constructivist theory.

\subsection{Social}

The contradiction between satisfaction of basic needs and the post-materialist characteristic of learner-centered teaching (Barkley, 2010) can be understood from a larger framework. Some issues such as «ideology, politics, and power are usually not considered in a psychological approach to constructivism such as they are in social constructivism» (Richardson, 2003: 1625). Under the lack of «sociological» perspective in constructivist teaching, there are issues besides basic material conditions. For instance, commodification of education and requirement of skills based on competencies, as many institutions embrace, do not fit with constructivist principles (Carney, 2008; Schweitzer y Stephenson, 2008). Likewise, according to Tabulawa (2003), learner-centered teaching is a project of democratization of society to create the basis of neo-liberalism as a development paradigm imposed to periphery states. According to this author, «learner-centered pedagogy is a political artifact, an ideology, a worldview of how society should be organized» (p. 10). 
It is clear that if the learner-centered approach aims to have a wide scope and broad acceptance, including at the international level, contextualization is necessary. There are still serious challenges in educational systems in developing countries related to very basic conditions (UNESCO, 2014). Basic, foundational needs in and out of classrooms still must be satisfied. In her studies of the United Republic of Tanzania, for example, Vavrus (2009) lays out that, «for instance, it is difficult to appreciate the utility of teacher-centered teaching unless one has taught in an overcrowded and undersupplied classroom» (p. 310). This type of reality raises some contradictory aspects of student-centered education that need to be considered. Schweitzer and Stephenson (2008) put forward the following three paradoxes regarding constructivism as an approach to teaching.

Paradox of professionalization: the constructivist perspective assumes active students capable of choosing their own ways to learn and work and to make some sense of the content. For instance, students do not need to hear examples, they need to identify and/ or construct them (Weimer 2013). The authors cast doubt on the viability of this idea and argue that students are not really free to choose ways of learning and content because they tend to see their own learning process only technically and as a function of academic credentials. In this regard, students are more focused on how much a teacher knows and how much content the teacher can provide. Students bave a content-centered expectation, rather than a willingness to develop other perspectives and abilities, including taking responsibility for their learning.

Paradox of privilege: the constructivist perspective assumes that it is possible to create democratic and egalitarian contexts but does not consider that some learners may come from privileged backgrounds. In this case, there is not a need for empowering because students do not come from marginal or excluded social groups. This paradox also emerges with «consumer-oriented students» who probably will not view a classroom as a democratic venue.

Paradox of authority: horizontal relationships are a desirable thread of the constructivist perspective. However, there are socio-psychological reasons to take into consideration issues regarding group dynamics. Often times, hierarchies are part of a governance system in an organization, including in schools and classrooms. For example, there are statuses based on age and experience which regularly claim and/or are granted positions of superiority. As the authors claim «removing authority provides no guarantee that equity or justice will follow» (p. 592).

However, society might not be the crucial unit of analysis. Within societies (i.e. nation-states) there are multiple structural realities. Organizations present themselves as interesting centers of social dynamics, as pertinent contexts or conditions.

\subsection{Organizational}

We know that any formal educational organization is constrained by public policies and regulations that set expectations and establish norms of conduct, content that must be covered/taught and indicators of efficacy and efficiency. Internally, these types of organizations have established their own additional constraints by, for example, the pedagogical models they have adopted. Additionally, the content of one course is expected to be connected to other courses, which pushes teachers to take a content-centered approach to teaching. This issue is critical because there are some responsibilities teachers have toward students and pedagogical projects that are evaluated not only on the basis of ethical criteria, but also from a consumer point of view. Therefore, it is a collective task, with several 
external and internal conditions, to define how much content should be taught and what to emphasize. This is not a trivial issue according to Ridgway and colleagues (2007), as they comment on the framework for designing curriculum for teaching statistics in the UK:

We believe that the current statistics curriculum is inadequate to equip students to become informed citizens in the $21^{\text {st }}$ century, where they will be required to reason from complex data sets. Indeed, the current situation poses a threat to democracy. If politicians claim to base policy on evidence, and use models that require some sophisticated statistical understanding, and if citizens are unable to understand these arguments, then a gap can emerge between the government and the governed. (47)

As there are expectations from formal educational organizations, there are also expectations, as mentioned before, for statistics teachers to undertake innovative strategies. Given numerous organizational constraints, the question arises: «is real innovation possible?» For instance, many learnercentered activities become very difficult to implement in highly-competitive educational environments because they require a different timing and more human resources that often are not available, among other factors. Another example is found in the learning skills development concept put forward by Weimer (2013) which requires that courses be related to each other and that students not experience «learner-centered teaching» by chance. While teacher communities are a good means for coordination and developing systematic approaches to teaching and learning, they require specific conditions, such as incentives and leadership.

\subsection{Cultural-Ideology}

Culture casts doubts on several taken-for-granted issues in teaching practices. For instance, certain skills can be useful in some contexts but not necessarily form part of what is considered «intelligence» in an academic context. Or, some skills are not directly measurable by academic tests because items on standard tests are processed in various ways by specific groups of students, say males and females or different ethnic groups (Sternberg, 2007).

Indeed, under specific cultural schemas, a learner-centered approach can be the wrong strategy. Kirschner and colleagues (2006) argue that a «minimally guided approach» is not a panacea. They even state that «there is also evidence that it may have negative results when students acquire misconceptions or incomplete or disorganized knowledge» (p. 84).

This statement can lead us into a heated discussion about the learner-centered approach. However, that is not the focus of this work. The idea here is to consider cultural aspects that boost or hinder initiatives for new techniques to curriculum innovation based on a more active role of students. Regardless the magnitude of changes, any educational approach based on a constructivist perspective should contemplate a mobilization of the whole educational system, including sociocultural aspects within classrooms (Nkosana, 2013). According to Vavrus (2009), the learner-centered approach is a general pedagogical project comprised of cultural, economic, and political forces that, worldwide, privilege certain approaches to pedagogy. However, the author argues that the diffusion of pedagogical styles happens regardless of considerable regional variability in the notion of «excellent teaching» and particular ways to achieve it.

Another cultural issue that is embraced by this work is the relationship between ideology and science in the teaching of statistics. Empirical social sciences were born as a mimesis of natural sciences 
in the social realm. In this regard, social phenomena were studied insofar as there was quantitative evidence.

In the 1950s there was a paroxysm with respect to the use of statistics in American sociology. Statistical representation of reality reached not only the scholarly community, but also governmental agencies and the mass media. Amidst this trend, it raised important points of criticism. One of the opponents, Pitirim Sorokin (1956), argued that psycho-social sciences suffered from an illness regarding teaching and the use of statistics. He called this phenomenon «the age of quantophrenia and numerology» (p. 103). With respect to teaching, and specifically statistics, in the psycho-social sciences, he comments on graduate formation follow.

Of all the courses in the departments of the psycho-social sciences, a course in statistics is often the only one required from all students in these departments. Being ignorant in the history, theory, methods, and other fundamentals of sociology and psychology, they still can get their Ph.D. with high honors if they know elementary statistics. (p. 105).

In 1959, C. Wright Mills (2000) did something similar. He laid out his criticism toward the way that sociology was building knowledge. In his view, public opinion studies had become a crucial part of scientific social knowledge, being highly technical and quantitative but without theoretical underpinnings. For instance, concepts such as «relation» are confined to statistical relations in an ahistorical way. Mills called the abuse of statistics «abstracted empiricism.» This implies that there is only one way of observing society, through the empiricist approach of the natural scientists. The main consequence is that there is a unique vision and meaning of science, which is synonymous with "The Scientific Method.»

This criticism toward quantitative methods has been formulated even more radically by Latin American scholars (Santos, 2009). In Latin American academia generally and particularly the teaching of methods and social research, there is a strong, widespread position against positivism as epistemological principle and functionalism as a theoretical framework.

This paper does not delve into an epistemological and theoretical debate about the influence of quantitative social sciences in Latin America. However, it is worthwhile to note that teaching has been a mediator between this criticism and students. The result has been some hostility against quantitative methods which might be one important source of low student performance in statistics courses in Latin America.

\section{Synthesis: Learner-centered Teaching According to Different Levels of Analysis}

In this brief literature review, four aspects of teaching have been highlighted: namely, students' psychological traits, subject content, teacher's role, and assessment. Also, three dimensions that constrain these aspects were identified: namely, social, cultural, and organizational.

The connection between these four aspects and three dimensions can be summarized in Table I. Each aspect is associated with each dimension. Each cell shows relevant topics or eventual findings that might be interesting to investigate. 


\section{Table I. Issues and findings according to both «aspects of teaching" and "constrain dimensions»}

\begin{tabular}{llll}
\multicolumn{1}{c}{ SOCIAL } & \multicolumn{1}{c}{ CULTURAL } & \multicolumn{1}{c}{ ORGANIZATIONAL } \\
\hline $\begin{array}{l}\text { Students } \\
\text { Psychological Traits }\end{array}$ & $\begin{array}{l}\text { Habitus: embodied sense of the world (disposi- } \\
\text { tions) acquired throughout socialization (Sallaz y y } \\
\text { Zavisca, 2007). Paradox of Privilege. }\end{array}$ & $\begin{array}{l}\text { Attitude toward positivism and quantitative } \\
\text { research. Math resistance and culture of fear, } \\
\text { producing anxiety. }\end{array}$ & $\begin{array}{l}\text { Flexibility of academic track, penalties for failure, } \\
\text { timing of courses to implement a developmental } \\
\text { design, supply of courses, etc. }\end{array}$ \\
\hline \multirow{2}{*}{ Content } & $\begin{array}{l}\text { Influence of labor competencies required by iob } \\
\text { market. }\end{array}$ & $\begin{array}{l}\text { Amount and difficulty of content related to } \\
\text { «disciplinary pride.» }\end{array}$ & $\begin{array}{l}\text { Relationship of content with other courses or } \\
\text { national/international standards. }\end{array}$ \\
\hline Teacher's Role & $\begin{array}{l}\text { Conditions of profession (prestige, rewards, labor } \\
\text { market, etc.) }\end{array}$ & $\begin{array}{l}\text { Expectations of students } \\
\text { Status of teaching in academic career. }\end{array}$ & $\begin{array}{l}\text { Internal conditions of labor, multitask teachers, } \\
\text { incentives, etc. Paradox of authority. }\end{array}$ \\
\hline \multirow{2}{*}{ Assessment } & $\begin{array}{l}\text { Credentialism (Collins, 1979) and the promi- } \\
\text { nence of academic achievement. }\end{array}$ & Grades as synonymous with evaluation. & Organizational prestige. \\
\hline
\end{tabular}

Source: Authors.

Considering Table I, there are several issues (cells) that pertain to this article. These issues can serve as starting points for future research questions. For instance, considering the first cell that emerges from students' psychological traits and social dimension, it might be valuable to study how learner-centered teaching strategies can be applied considering different students' cultural and educational backgrounds. Or, considering the cell that results from content and organizational dimension, it might be interesting to understand how statistics contents are bound by the human resources that different educational organizations have. These are only two examples of a list of at least 12 questions (one per cell) that can emerge from Table I.

This synthesis aims to foster research about learner-centered teaching approach in different contexts (subjects, communities, etc.) and from different fields of the social sciences. The ultimate goal is to enrich the discussion based on empirical evidence and to go beyond theoretical reflection or anecdotal knowledge.

\section{Discussion}

This work has presented a review of the main elements of learner-centered teaching as a thriving approach at college level. Known scholars have demonstrated its efficacy and valuable efforts has been carried out in the social sciences. There are still disagreements regarding the role of that type of teaching approach should play to improve the teaching of more structured subjects like statistics. In this regard, we explored the question about the possibility of fostering active learning and critical thinking in math or statistics classes.

Several issues need to be considered when we analyze teaching of statistics in order to foster active learning. Some of them are shared with other contents, but there are some which are specific to teaching statistics. Regarding the latter, some considerations are related to statistics itself and others to the interpretative processes that students undergo when they see themselves studying that subject. The aforementioned considerations were taken from theoretical postulates of the learner-centered approach such as students' psychological traits or teachers' role.

However, there are some caveats with respect to the viability of the learner-centered teaching approach which apply to statistics classes. Apart from some skeptical positions with respect to certain theoretical principles of this teaching approach, there are other questions related to its viability in specific contexts. In this article, we contemplated three common level of analysis used in the social sciences to delimit specific contexts (social, cultural and organizational) and phenomena in the teaching of statistics. 
In this way, it is possible to review more analytically what active learning and active learners mean. This paper responded by opening the concept of active learner and critical thinking to empirical evidence in order to enrich its more general theoretical principles. In doing this, a spectrum of applications and results around learner-centered teaching can be explored through future research.

\section{Bibliographic references}

Auster, Carol J. (2000): "Probability Sampling and Inferential Statistics: An Interactive Exercise Using M\&M's." Teaching Sociology, 28 (4), 379-385. doi:10.2307/1318587

Barkley, Elizabeth (2010). Student Engagement Techniques. A Handbook for College Faculty. San Francisco, US: Jossey-Bass.

Bessant, Kenneth C. (1992): "Instructional Design and the Development of Statistical Literacy." Teaching Sociology, 20 (2), 143-149. doi:10.2307/1317398

Blalock, H.M. (1987). "Some General Goals in Teaching Statistics.” Teaching Sociology, 15 (2), 164-172. doi:10.2307/1318031

Carney, Stephen (2008). "Learner-centred pedagogy in Tibet: International education reform in a local context." Comparative Education, 44 (1), 39-55. doi:10.1080/03050060701809417

Castells, Manuel (2004). The Network Society. UK and USA: Edward Elgar.

Collins, Randall (1979). The Credential Society: An Historical Sociology of Education and Stratification. New York: Academic Press.

De Maio, Fernando (2014): "Regression Analysis and the Sociological Imagination." Teaching Statistics, 36 (2), 52-57. doi:10.1111/test.12019

DeCesare, Michael (2007): “«Statistics Anxiety» Among Sociology Majors: A First Diagnosis and Some Treatment Options.” Teaching Sociology, 35 (4), 360-367. doi:10.1177/0092055X0703500405

Delucchi, Michael (2007): "Assessing the impact of group projects on examination performance in social statistics.” Teaching in Higher Education, 12 (4), 447-460. doi:10.1080/13562510701415383

Delucchi, Michael (2014). "Measuring Student Learning in Social Statistics: A Pretest-Posttest Study of Knowledge Gain.” Teaching Sociology, 42 (3), 231-239. doi:10.1177/0092055X14527909

Halley, Fred S. (1991): “Teaching Social Statistics with Simulated Data.” Teaching Sociology, 19 (4), 518-525. doi:10.2307/1317899

Helmericks, Steven (1993): “Collaborative Testing in Social Statistics: Toward Gemeinstat.” Teaching Sociology, 21 (3), 287-297. Recuperado de: http://www.jstor.org/stable/1319027

Hurlburt, Russell T. (1993): 'Developing Estimation Skills to Increase Students' Comprehension of the Mean and the Standard Deviation.” Teaching Sociology, 21 (2), 177. doi:10.2307/1318640

Kaplan, Leslie y Owings, William (2013). Culture Re-Boot. Reinvigorating School Culture to Improve Student Outcomes. US: Sage Publications Ltd.

Karp, David R. (1995): “Using SPSS for Windows to Enhance, Not Overwhelm, Course Content.” Teaching Sociology, 23 (3), 234. doi:10.2307/1319215 
Keating, AnaLouise (2007). Teaching Transformation. Transcultural Classroom Dialogues. New York, USA.: Palgrave Macmillan.

Kirschner, Paul; Sweller, John and Clark, Richard (2006): "Cognitive Architectures for Multimedia Learning Cognitive Architectures for Multimedia Learning." Educational Psychologist, 41(2), 87-98. doi:10.1207/ s15326985ep4102

Macheski, G. E.; Buhrmann, J.; Lowney, K. S. and Bush, M. E. L. (2008): "Overcoming Student Disengagement and Anxiety in Theory, Methods, and Statistics Courses by Building a Community of Learners.” Teaching Sociology, 36 (1), 42-48. doi:10.1177/0092055X0803600106

Markham, William T. (1991): "Research Methods in the Introductory Course: To Be or Not to Be?" Teaching Sociology, 19 (4), 464-472. doi:10.2307/1317888

Masika, Rachel and Jones, Jennie. (2016): "Building student belonging and engagement: insights into higher education students' experiences of participating and learning together." Teaching in Higher Education, 21 (2), 138-150. doi:10.1080/13562517.2015.1122585

Mills, C. Wright. (2000). Sociological Imagination. New York: Oxford University Press.

Neuman, W.Lawrence (1989): "Which Students Learn the Most, and Why? A Replication and Extension of the Szafran Pretest Study.” Teaching Sociology, 17 (1), 19-27. doi:10.2307/1317921

Nkosana, Leonard Mwalimu (2013): “Educational Reform in Third World Countries.” International Journal of African and Asian Studies, 2, 1-10.

Onwuegbuzie, Anthony J. and Wilson, Vicki A. (2003): "Statistics Anxiety: Nature, etiology, antecedents, effects, and treatments - A comprehensive review of the literature." Teaching in Higher Education, 8 (2), 195-209. doi:10.1080/1356251032000052447

Paxton, Pamela (2006): "Dollars and Sense: Convincing Students That They Can Learn and Want to Learn Statistics.” Teaching Sociology, 34(1), 65-70. doi:10.1177/0092055X0603400106

Potter, Alisa M. (1995): "Statistics for Sociologists: Teaching Techniques That Work." Teaching Sociology, 23 (3), 259-263. doi:10.2307/1319218

Renta-Davids, Ana Inés; Jiménez-González, José Miguel; Fandos Garrido, Manel and González Soto, Ángel Pío. (2016): “Organisational and Training Factors Affecting Academic Teacher Training Outcomes.” Teaching in Higher Education, 21 (2), 219-231. doi:10.1080/13562517.2015.1136276

Richardson, Virginia (2003): “Constructivist Pedagogy.” Teachers Collegege Record, 9(105), 1623-1640. Recuperado de: http://www.tcrecord.org/content.asp?contentid=11559

Ridgway, Jim; Nicholson, James and McCusker, Sean (2007): “Teaching Statistics? Despite Its Applications." Teaching Statistics, 29 (2), 44-48. doi:10.1111/j.1467-9639.2007.00276.x

Sallaz, Jeffrey J. and Zavisca, Jane (2007): “Bourdieu in American Sociology, 1980-2004.” Annual Review of Sociology, 33 (1), 21-41. doi:10.1146/annurev.soc.33.040406.131627

Santos, Boaventura de Sousa (2009). Una Epistemologia del Sur. La reinvencion del Conocimiento y la Emancipacion Social. Mexico, D.F.: CLACSO-Siglo XXI. 
Schacht, Steven and Stewart, Brad (1992): "Interactive/User-Friendly Gimmicks for Teaching Statistics." Teaching Sociology, 20 (4), 329-332. Recuperado de: http://www.jstor.org/stable/1318981

Schacht, Steven and Stewart, Brad J. (1990): "What's Funny about Statistics? A Technique for Reducing Student Anxiety.” Teaching Sociology, 18 (1), 52-56. doi:10.2307/1318231

Schumm, Walter R.; Webb, Farrell J.; Castelo, Carlos S.; Akagi, Cynthia G.; Jensen, Erick J.; Ditto, Rose M.; Spencer Carver, Elaine and Brown, Beverlyn F. (2002): "Enhancing Learning in Statistics Classes through the Use of Concrete Historical Examples: The Space Shuttle Challenger, Pearl Harbor, and the RMS Titanic.” Teaching Sociology, 30 (3), 361-375. doi:10.2307/3211484

Schweitzer, Lisa and Stephenson, Max (2008): "Charting the challenges and paradoxes of constructivism: a view from professional education." Teaching in Higher Education, 13(5), 583-593. doi:10.1080/13562510802334947

Smith, Brad (2003): "Using and Evaluating Resampling Simulations in SPSS and Excel." Teaching Sociology, 31 (3), 276-287. doi:10.2307/3211325

Sorokin, Pitirim (1956). Fads and Foibles in Modern Sociology. Chicago: Henry Regnery Company.

Sternberg, Robert J. (2007): “Culture, instruction, and assessment." Comparative Education, 43 (1), 5-22. doi:10.1080/03050060601162370

Strangfeld, Jennifer A. (2013): "Promoting Active Learning: Student-Led Data Gathering in Undergraduate Statistics.” Teaching Sociology, 41 (2), 199-206. doi:10.1177/0092055X12472492

Tabulawa, Richard (2003): "International Aid Agencies, Learner-centred Pedagogy and Political Democratisation: A critique.” Comparative Education, 39 (1), 7-26. doi:10.1080/03050060302559

Timpson, William and Burgoyne, Suzanne (1982). Teaching \& Performing: Ideas for Energizing Your Classes. Madison, WI: Magna Publications.

Tobias, Sheila (1987). Succeded with Math. New York: The College Board.

UNESCO. (2014). Teaching and Learning: Achieving Quality for All. Paris, France: Recuperado de http:// unesdoc.unesco.org/images/0022/002266/226662e.pdf

Vavrus, Frances (2009): “The cultural politics of constructivist pedagogies: Teacher education reform in the United Republic of Tanzania." International Journal of Educational Development, 29 (3), 303-311. doi:10.1016/j.ijedudev.2008.05.002

Weimer, Maryellen (2013). Learner-Centered Teaching. Key Changes to Practice. San Francisco, US: Jossey-Bass.

Wilder, Esther Isabelle (2010): “A Qualitative Assessment of Efforts to Integrate Data Analysis throughout the Sociology Curriculum: Feedback from Students, Faculty, and Alumni." Teaching Sociology, 38 (3), 226-246. doi:10.1177/0092055X10370118

Wybraniec, John and Wilmoth, Janet. (1999): “Teaching Students Inferential Statistics: A «Tail» of Three Distributions.” Teaching Sociology, 27 (1), 74-80. doi:10.2307/1319249

Yilmaz, Kaya. (2008): "Constructivism: Its Underpinnings, Variations, and Implications for classroom Instruction.” Educational Horizons, 86(3), 161-172. Recuperado de: http://www.jstor.org/stable/ i40112299 


\section{Biographical notes}

Celestino Fernández. For 39 years, Dr. Celestino Fernández served as Professor of Sociology at the University of Arizona, where he also held various administrative positions, including Vice-President for Academic Outreach and International Affairs. In 2015, he was appointed Distinguished Professor Emeritus. He also holds the position of PIMSA Distinguished Professor at CETYS Universidad (Mexico). He has published some 50 articles and chapters in academic journals and books, several of them on topics pertaining to higher education. Prof. Fernández received a Master's and Doctorate in Sociology from Stanford University.

Ricardo Rivas is a PhD candidate in Sociology at the University of Arizona, USA. He is associate scholar at the Center for Communication, Discourse and Power Research, University of La Frontera, Chile. 